\title{
Design Contemporâneo e Inovação social aplicados no desenvolvimento de produtos gráficos educativos para pessoas com deficiência visual Contemporary Design and Social Innovation applied in the development of graphic educational products for people with visual impairment
}

\author{
Mônica Moura, Cristina Portugal, Iana Uliana Perez, Maria Alice Torres \& Márcio \\ Guimarães
}

\begin{abstract}
design contemporâneo, inovação social, design gráfico inclusivo, design educação, deficiência visual,
\end{abstract} open design.

\begin{abstract}
$\mathrm{Na}$ abrangência e diversidade do Design Contemporâneo, um dos aspectos que tem tomado corpo nos estudos, pesquisas e aplicações projetuais é o design com responsabilidade social, que envolve a inovação nos métodos e processos visando a inclusão de grupos sociais por meio da aquisição de conhecimentos e capacitação para autonomia do indivíduo. Nesse âmbito, o projeto de pesquisa aqui apresentado visa a investigação sobre o Design Gráfico Contemporâneo e suas áreas dialógicas Responsabilidade e Inovação Social, Inclusão, Educação, Deficiência Visual e Open Design - examinando os processos de aquisição de conhecimentos, de ensino-aprendizagem, da fabricação digital e dos sistemas abertos para disseminação em livre acesso de informações resultantes dos estudos e das produções desenvolvidas e dos resultados obtidos. Dessa maneira, pretende-se desenvolver ações de Design Gráfico direcionadas para processos de ensino-aprendizagem envolvendo a cultura e a tecnologia a partir da produção de produtos educativos em formato de peças gráficas táteis impressas que contribuam para a inclusão de pessoas com deficiência visual (indivíduos com baixa visão, cegueira congênita ou adquirida). Ademais, considera os educadores que atuam com a população atendida por instituições especializadas em deficiência visual localizadas nas cidades de Bauru, São Paulo, São Luís, Rio de Janeiro que serão participantes nesse projeto.
\end{abstract}

contemporary design, social innovation, inclusive graphic design, education design, visual impairment, open design.

\begin{abstract}
In the scope and diversity of Contemporary Design, one of the aspects that has taken shape in studies, research and design applications is socially responsible design, which involves innovation in methods and processes aimed at the inclusion of social groups through the acquisition of knowledge and empowerment of the individual and the free access to the results obtained. In this context, the research project presented here is aimed at researching Contemporary Graphic Design and its dialogic areas - Social Responsibility and Innovation, Inclusion, Education, Visual Deficiency and Open Design - examining the processes of acquisition of knowledge, learning, digital manufacturing and open systems for the dissemination of information resulting from studies and developed productions. In this way, the intention is to develop Graphic Design actions directed to teaching-learning processes involving culture and technology from the production of educational products in the form of printed tactile graphic pieces that contribute to the inclusion of people with visual impairment (individuals with low vision, congenital or acquired blindness). Besides, it considers the educators who work with the population attended by institutions specialized in visual impairment located in the cities of Bauru, São Paulo, São Luís, Rio de Janeiro, which will be participants in this project.
\end{abstract}

\section{Introdução}

Na abrangência e diversidade do design contemporâneo, um dos aspectos que tem tomado corpo nos estudos, pesquisas e aplicações projetuais é o design com responsabilidade social, que envolve a inovação nos métodos e processos favorecendo a participação ativa e a inclusão. Dessa forma, atende a populações e grupos sociais visando a melhoria para a aquisição de conhecimentos e capacitação para autonomia do indivíduo.

Anais do 9 $\mathrm{CIDI}$ e 9 CONGIC

Luciane Maria Fadel, Carla Spinillo, Anderson Horta, Cristina Portugal (orgs.)

Sociedade Brasileira de Design da Informação - SBDI Belo Horizonte | Brasil | 2019

ISBN $978-85-212-1728-2$
Proceedings of the 9th CIDI and 9th CONGIC

Luciane Maria Fadel, Carla Spinillo, Anderson Horta, Cristina Portugal (orgs.)

Sociedade Brasileira de Design da Informação - SBDI Belo Horizonte | Brazil | 2019

ISBN 978-85-212-1728-2 
Moura M., Portugal, C., Perez, I., Torres, M. A. \& Guimarães, M. | Design Contemporâneo e Inovação social aplicados no desenvolvimento de produtos gráficos educativos para pessoas com deficiência visual

Essa pesquisa visa a investigação sobre o Design Gráfico Contemporâneo e suas áreas dialógicas - sendo elas: responsabilidade e inovação social, inclusão, educação, memórias e histórias de vida, deficiência visual e open design - examinando os processos de aquisição de informações e conhecimentos, de ensino-aprendizagem, da fabricação digital e dos sistemas abertos para disseminação de informações resultantes dos estudos e das produções desenvolvidas. Dessa maneira, pretende-se desenvolver ações efetivas de Design Gráfico direcionadas para processos de ensino-aprendizagem envolvendo a cultura e a tecnologia a partir da produção de produtos gráficos informativos e educativos que contribuam para a inclusão de pessoas com deficiência visual (indivíduos com baixa visão, cegueira congênita ou adquirida) e, também, abarca os educadores que atuam com a população atendida por instituições especializadas em deficiência visual, inicialmente, localizadas na cidade de Bauru e, a partir dos resultados obtidos e validados, será realizada a aplicação em outras instituições parceiras do projeto, localizadas nas cidades de São Paulo, São Luís e Rio de Janeiro. Os ambientes envolvidos para o desenvolvimento e as produções advindas dessa pesquisa envolvem a Universidade Estadual Paulista (UNESP) e a Universidade Federal do Maranhão (UFMA) e o Laboratório Interdisciplinar de Design/Educação (LIDE), como responsável pelo LIDE neste projeto a profa. Dra. Cristina Portugal, onde diferentes laboratórios e grupos de pesquisa se articulam em torno dessa proposta em diferentes modalidades de investigação iniciação científica, mestrado, doutorado e docência.

No Brasil, o número de cidadãos diagnosticados com cegueira ultrapassou a marca de meio milhão de pessoas (IBGE, 2010). Definimos nosso campo de atuação junto a este público, pois entendemos que o Design como área científica integra conhecimentos interdisciplinares, tornando-se instrumento efetivo na construção de estratégias e critérios de avaliação e desenvolvimento de projetos adequados às necessidades de acessibilidade, oportunizando a educação inclusiva.

Essa pesquisa é de caráter qualitativo e envolve os seguintes aspectos metodológicos: pesquisa bibliográfica, pesquisa documental, pesquisa de campo, entrevistas semiestruturadas, coleta de dados, análise sistemática, ações projetuais, teste de validação e usabilidade, ajustes e validação final.

Neste artigo, é apresentada uma breve pesquisa teórica que foi empreendida com o intuito de entender as necessidades e possibilidades primordiais para atender pessoas cegas. Esta fundamentação teórica foi tomada por base para o desenvolvimento das entrevistas com o público alvo, capacitando a equipe a observá-lo com mais foco. Por fim, são apresentados os resultados parciais já obtidos por meio da pesquisa de campo empreendida junto ao Lar Escola Santa Luzia para Cegos, instituição localizada em Bauru, interior de São Paulo.

\section{Deficiência Visual: baixa visão e cegueira}

Segundo dados divulgados pelo Conselho Brasileiro de Oftalmologia (CBO, 2012) e pelo Instituto Brasileiro de Geografia e Estatística (IBGE, 2010), em seu último levantamento de informações sobre deficiências no Brasil, o número de cidadãos diagnosticados com cegueira ultrapassou a marca de meio milhão de pessoas. Destas, 33 mil são crianças em fase escolar.

Frente à esta realidade, torna-se necessário empregar iniciativas em diferentes âmbitos, como a tomada de ações preventivas em relação ao monitoramento e controle de doenças relacionadas à visão $e$, também, à implementação de práticas voltadas à promoção da qualidade de vida para as pessoas já diagnosticadas com deficiência visual, possibilitando-lhes acesso aos seus direitos básicos. Definimos nosso campo de atuação junto a este público, pois entendemos que o Design como área científica integra conhecimentos interdisciplinares, tornando-se instrumento efetivo na construção de estratégias e critérios de avaliação e desenvolvimento de projetos adequados às necessidades de acessibilidade, oportunizando a educação inclusiva.

A princípio, procuramos compreender o processo fisiológico da visão e os aspectos e processos cognitivos relacionados ao ato de ver, e de como estes se comportam em casos de insuficiência ou ausência da visão. Identificamos e passamos a compreender melhor como a 
Moura M., Portugal, C., Perez, I., Torres, M. A. \& Guimarães, M. | Design Contemporâneo e Inovação social aplicados no desenvolvimento de produtos gráficos educativos para pessoas com deficiência visual

"experiência visual" se dá por meio da experiência háptica (reconhecimento em profundidade de aspectos relacionados a textura, temperatura, volume e peso), permitindo aos cegos e às pessoas com baixa visão em graus mais severos, a capacidade de reconhecimento e memorização das coisas, produzindo uma imagem mental limitada, pois a pessoa nestas condições percebe com totalidade apenas os objetos que cabem na palma de suas mãos, limite de sua percepção háptica (Cardeal, 2008; Darras \& Valente, 2011; Duarte, 2011; Griffin \& Gerber, 1996; Kastrup, 2007; Nuernberg, 2010 ).

Já a pessoa com baixa visão, por utilizar um pequeno potencial visual para explorar ambientes, pode, em alguns casos, identificar objetos, ler e escrever; mas, assim como as cegas, fazem uso dos outros sentidos como auxílio à construção cognitiva e também são alfabetizadas pelo sistema Braille, que se configura essencial à sua autonomia quando em condições ambientais desfavoráveis à leitura visual.

As principais limitações que a deficiência visual impõe ao processo de desenvolvimento de aprendizagem referem-se ao controle do ambiente, organização e orientação do espaço. As pessoas com deficiência visual desenvolvem significados e dão sentido às coisas que exploram pelo uso dos sentidos de forma integrada. O estímulo à coordenação sensório-motora proporciona-lhes independência e lhes torna aptas ao aprendizado constante, como o desenvolvimento da percepção háptica, a percepção ativa do toque integrada aos demais sentidos, melhorando, assim, suas habilidades e interesses na decodificação de objetos, eventos e situações (Bruno, 2006, p. 44).

\section{Metodologia proposta}

Os aspectos metodológicos empregados têm como guia o objetivo geral proposto nesse projeto de pesquisa, envolvendo pesquisa bibliográfica, pesquisa documental, entrevistas, observação e ações projetuais. A pesquisa bibliográfica envolve estudos já desenvolvidos, aos quais somam-se outros autores e referenciais para análises, avaliações, interpretações e ações projetuais. Essa ação é repetida periodicamente, devido à relevância e atualidade do tema. Portanto, desenvolve-se a partir de autores já citados neste projeto, acrescentando-se livros, artigos e teses recentes, assim como consultas e levantamentos oriundos de bases de dados nacionais e internacionais, nas áreas de design, educação, inclusão, deficiência visual, inovação social e open design.

A avaliação de produtos e materiais dá-se a partir da organização de Protocolo de Registro de Informações, baseado nos estudos de Cardeal (2011) associados a Adam e Calomeno (2014), que propõem uma metodologia de design centrada no usuário aplicada a análise de projetos editoriais com o propósito de melhor atender suas necessidades. Desta maneira, estima-se, com esta investigação, avaliar e apontar diretrizes para a produção dos produtos e materiais gráficos inclusivos. O registro de uso dos artefatos analisados é feito por filmagem e registros fotográficos com enquadramento apenas das mãos da pcd visual. Ademais, têm-se desenvolvido pesquisa de campo com entrevistas e observação/participação junto às instituições de educação para cegos envolvidas no projeto, o público formado pelas pessoas com deficiência visual e os professores que atuam nessas instituições. A primeira instituição envolvida, junto a qual os procedimentos metodológicos têm sido testados, é o Lar Escola Santa Luzia, em Bauru. Futuramente, serão também organizados grupos focais com pcds visual. A geração de procedimentos e metodologias se dará a partir das análises, interpretações e documentação dos processos adotados.

O desenvolvimento da ação projetual envolverá planejamento, definição de parâmetros e diretrizes projetuais, implementação dos materiais e processos produtivos, validação dos experimentos, adequações necessárias e finalização da produção. De forma concomitante, haverá a documentação das metodologias e procedimentos empregados para a geração de material digital visando a disseminação dos processos, técnicas e produtos gerados em sistemas abertos, denominados open design.

A reunião dos resultados, com as análises e interpretações, será tratada em redação científica e destinada a publicações para disseminação da pesquisa tanto para o público 
Moura M., Portugal, C., Perez, I., Torres, M. A. \& Guimarães, M. | Design Contemporâneo e Inovação social aplicados no desenvolvimento de produtos gráficos educativos para pessoas com deficiência visual

acadêmico quanto para pessoas leigas relacionadas ao objeto de pesquisa. Neste artigo, são apresentados os resultados parciais das entrevistas e observações já realizadas no Lar Escola Santa Luzia, as quais ainda estão sendo conduzidas. Atualmente, a instituição atende 74 pcd, das quais $16(21,6 \%)$ já foram entrevistadas, sendo os dados coletados por meio de áudio, anotações de campo e posterior preenchimento de formulário previamente estruturado. Também foram entrevistadas a assistente social e a pedagoga da instituição, com coleta de dados por meio de anotações, redação de relatório de campo e registro fotográfico dos materiais para aprendizagem de braille desenvolvidos pela pedagoga. Por fim, foram realizados testes de leitura de braille em papel e braille adaptado (alto relevo) com seis indivíduos divididos em três grupos: controle (sem diabetes), diabéticos assintomáticos (sem queixas de perda de sensibilidade nos dedos) e diabéticos sintomáticos (com queixa de perda de sensibilidade). Nesses testes, os dados foram coletados por meio de gravação de áudio, anotações de campo e registro em foto e vídeo das mãos durante a leitura. Ademais, previamente foi lido o Termo de Consentimento Livre e Esclarecido, atendendo à resolução CNS N ${ }^{\circ} 510$, e gravado o aceite dos participantes por áudio.

\section{Resultados parciais}

O Lar Escola atende prevalentemente pessoas em idade adulta (com mais de 18 anos), tendo iniciado apenas este ano um projeto para atendimento de crianças. As primeiras entrevistas com a população atendida pela instituição foram realizadas com a população idosa ou acima dos 50 anos, motivo pelo qual, na amostra de entrevistas já coletadas, há predomínio dessa faixa etária, como ilustra a Figura 1.

Figura 1: Faixa etária das pessoas com deficiência visual já entrevistadas

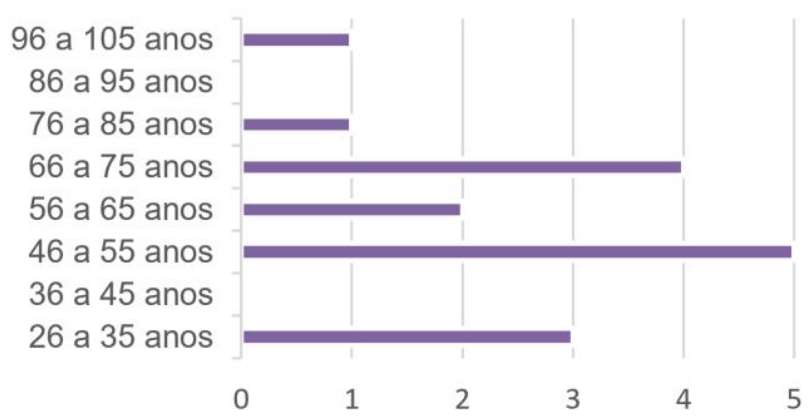

Sete dos entrevistados apresentam cegueira total $(43,8 \%)$, enquanto os demais ainda distinguem vultos, claridade, sombras ou cores. Na Figura 2, pode-se observar que a maioria $(81,25 \%)$ adquiriu a deficiência visual já na fase adulta ou após os 16 anos de idade. Dentre as causas relacionadas à aquisição da deficiência, destacam-se a diabetes $(31,25 \%)$, seguida por acidente $(25 \%)$ e glaucoma $(18,75 \%)$. Cabe citar que tanto o envelhecimento quanto a diabetes estão vinculados a algumas das principais causas de deficiência visual, como o glaucoma e a retinopatia diabética, respectivamente (Ávila, Alves \& Nishi, 2015; Castro et al., 2017). 
Moura M., Portugal, C., Perez, I., Torres, M. A. \& Guimarães, M. | Design Contemporâneo e Inovação social aplicados no desenvolvimento de produtos gráficos educativos para pessoas com deficiência visual

Figura 2: Caracterização da deficiência visual das pessoas entrevistadas
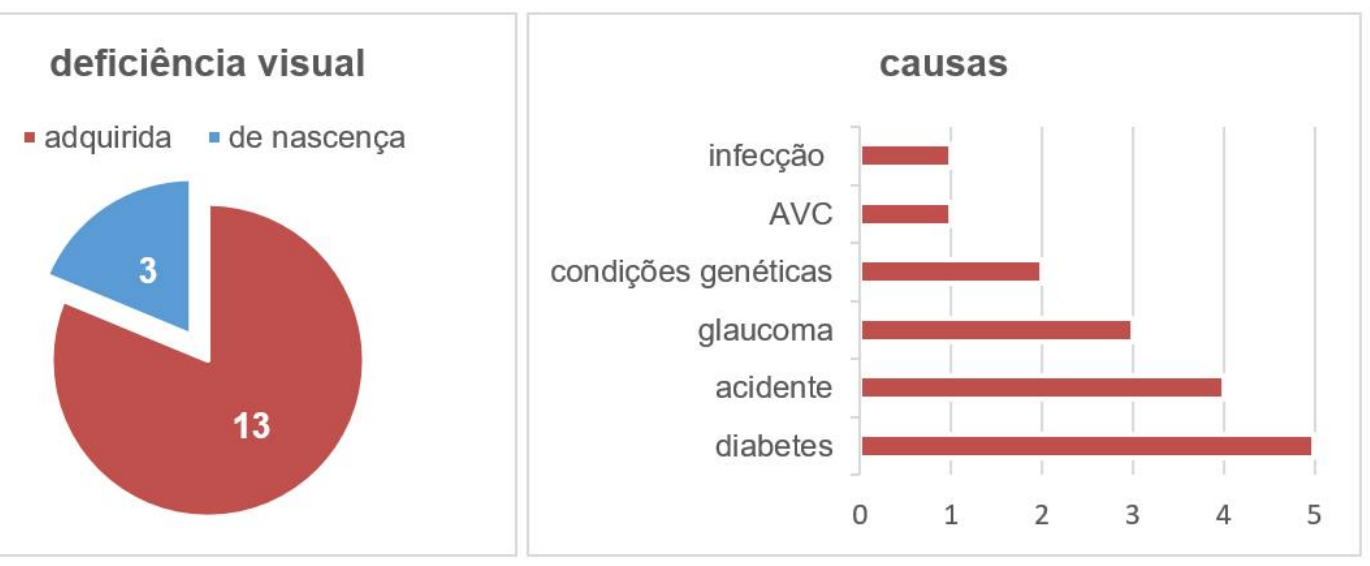

Tanto o envelhecimento quanto a diabetes podem estar relacionados à perda de sensibilidade nos dedos (neuropatia periférica). Essa é uma informação relevante considerando a população com deficiência visual que apresenta ou diabetes ou idade avançada, visto que a percepção tátil é um dos principais recursos utilizados por esses indivíduos no processo de aprendizagem. Nesse sentido, a Figura 3 destaca o nível de escolaridade e de aprendizagem em braille das pessoas entrevistadas. Observa-se que a maioria $(62,5 \%)$ parou os estudos ainda no ensino fundamental, sem necessariamente ter concluído esse nível (muitos relataram ter estudado apenas até a quarta ou quinta série, por exemplo), fator que pode interferir na aprendizagem do braille, pois, segundo a pedagoga, pessoas com baixa escolaridade ou analfabetas apresentam maior dificuldade. Contudo, parte expressiva dos entrevistados $(37,5 \%)$ relata ler e escrever bem em braille, enquanto alguns ainda estão em fase de aprendizagem e outros já encerraram ou interromperam a aprendizagem, mas ainda apresentam dificuldade na leitura ou escrita.

Figura 3: Nível de escolaridade e de aprendizagem em braille das pessoas entrevistadas

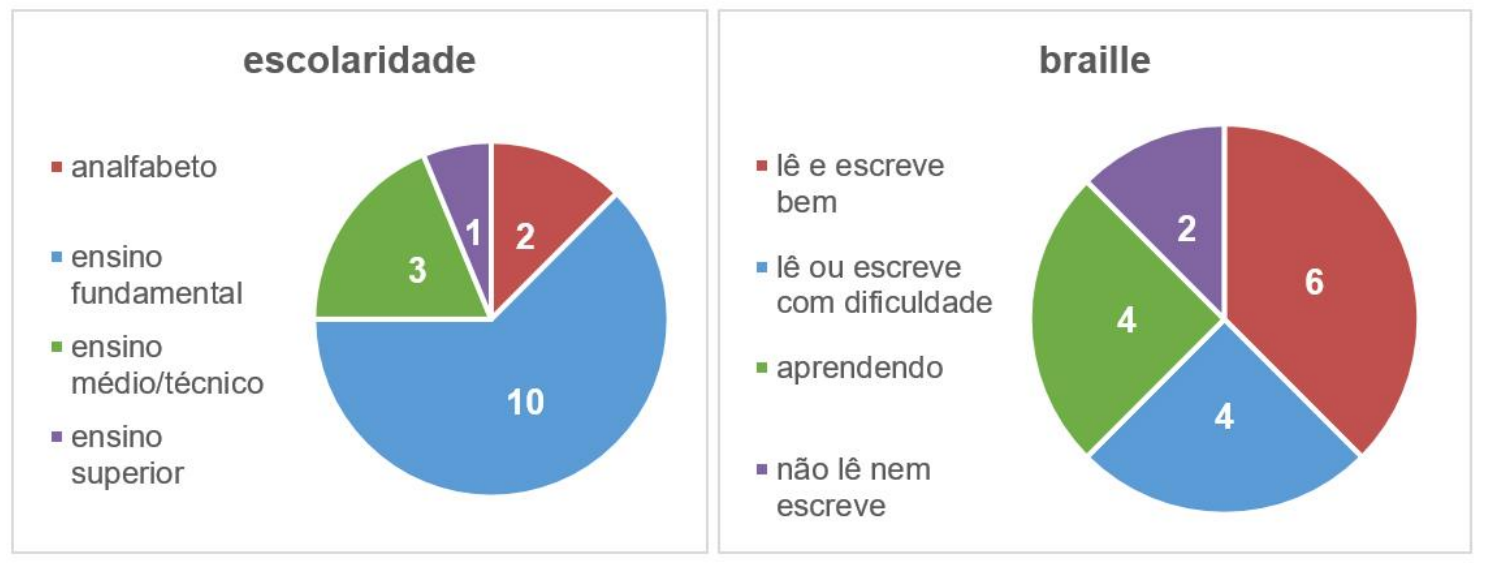

Dentre as queixas relacionadas à leitura do sistema braille, destacam-se: dificuldade de leitura por perda de percepção tátil ou de sensibilidade nos dedos $(n=4 ; 25 \%)$ e pontos do braille considerados muito pequenos e próximos ( $n=4 ; 25 \%)$, o que dificulta a distinção das células (equivalentes às letras no sistema braille). Houve também uma queixa relacionada à dificuldade de se aprender quando adulto (apenas um dos entrevistados aprendeu ainda na infância), o que corrobora a constatação de Cryer e Home (2011), para quem um dos principais fatores impeditivos para a aprendizagem do sistema braille é a idade em que ocorre esse processo, pois, quanto mais avançada, maior a dificuldade enfrentada. Já uma pessoa admitiu ter dificuldades por falta de treino, um dos fatores apontados pela pedagoga como possível barreira de progresso, o qual depende sobretudo da dedicação de cada aluno ("leitura é um

Anais do 9 Congresso Internacional de Design da Informação | CIDI 2019 
Moura M., Portugal, C., Perez, I., Torres, M. A. \& Guimarães, M. | Design Contemporâneo e Inovação social aplicados no desenvolvimento de produtos gráficos educativos para pessoas com deficiência visual

treino", segundo a pedagoga). Como as aulas de braille no Lar Escola ocorrem apenas uma vez por semana, os alunos devem treinar em casa nos demais dias, utilizando para isso os materiais para aprendizagem fornecidos pela pedagoga.

Outro fator que pode interferir na aprendizagem do braille, segundo Cryer e Home (2011), é o desenvolvimento da tecnologia, que leva muitos a acreditar que ela tem mais soluções a oferecer do que o braille. De fato, a maioria dos entrevistados utiliza alguma tecnologia, seja celular ( $n=14 ; 87,5 \%)$ ou computador $(n=6 ; 37,5 \%)$, mas não foram coletados relatos que indiquem uma tendência a considerar o braille menos importante que soluções tecnológicas.

De qualquer modo, o relatório de Cryer e Home (2011) enfatiza que, embora possa haver muitas queixas que relacionem a dificuldade de aprender braille à perda de sensibilidade nos dedos (neuropatia periférica), diversos outros fatores podem também interferir no processo de aprendizagem. Afinal, as descobertas de vários estudos, segundo os pesquisadores supracitados, mostram que a diminuição da sensibilidade não necessariamente impede a leitura tátil. Assim, a carga cognitiva de aprender o sistema braille, que é demasiadamente complexo, pode ser um fator mais decisivo do que a neuropatia, uma vez que há evidências da possibilidade de melhorar a sensibilidade tátil com a prática.

Nesse sentido, o Lar Escola oferece diversas atividades que tem como um dos principais objetivos apurar o tato de indivíduos com deficiência visual, destacando-se aqui as aulas de artesanato e o trançado em palha, além de atividades para desenvolvimento da coordenação motora global e fina. Como ilustra a Figura 4, essas atividades estão entre as principais apontadas pelos entrevistados como sendo as suas prediletas. Segundo a pedagoga, quando um aluno se queixa de perda de sensibilidade, ela o encaminha para uma dessas atividades.

Figura 4: Principais atividades desenvolvidas no Lar Escola segundo as pessoas entrevistadas.

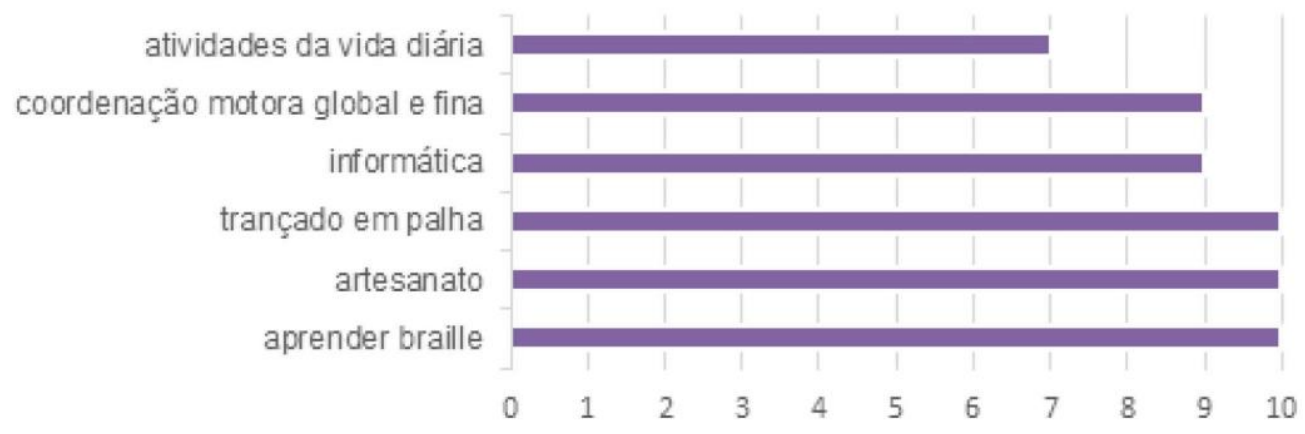

Ademais, a pedagoga do Lar Escola cria os próprios artefatos adaptados para ensino e aprendizagem de braille (Figura 5), utilizando técnicas artesanais e materiais diversos, produzindo recursos pedagógicos em diferentes tamanhos para facilitar a aprendizagem de quem tem dificuldade de distinguir os pontos do braille. Segundo a pedagoga, ela mesma produz esses artefatos seja por não existirem versões adaptadas em tamanhos maiores, seja porque os existentes são muito caros. Ela apresentou, por exemplo, alguns jogos educativos e outros recursos comerciais para aprendizagem cujo relevo do braille, por ser muito discreto, dificulta a leitura tátil. Assim, ela busca criar o máximo possível para favorecer a aprendizagem, iniciando o processo com os materiais adaptados de maior relevo, de forma a ir diminuindo gradativamente o tamanho dos pontos até poder introduzir a escrita e a leitura de braille utilizando a reglete (instrumento para escrita de braille convencional, o qual adota como padrão um relevo mais baixo em relação aos materiais adaptados). 
Moura M., Portugal, C., Perez, I., Torres, M. A. \& Guimarães, M. | Design Contemporâneo e Inovação social aplicados no desenvolvimento de produtos gráficos educativos para pessoas com deficiência visual

Figura 5: Artefatos adaptados para ensino de braille (a-e) e braille impresso sobre papel utilizando reglete (f).
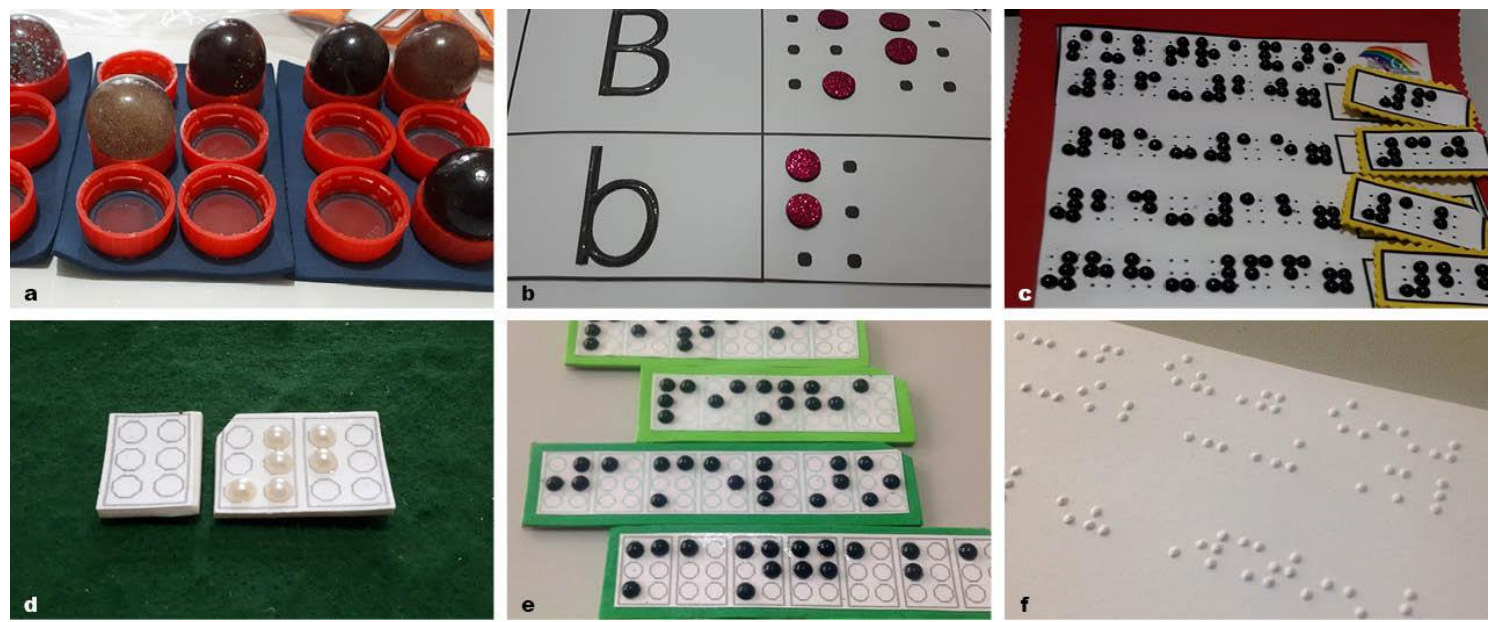

Para testar, de maneira experimental, a eficácia desses artefatos na leitura do braille, foram selecionados o braille adaptado da imagem "e", que consiste em peças de EVA com semiesferas de plástico ABS de $5 \mathrm{~mm}$ de diâmetro coladas em sua superfície, formando células braille combinadas em palavras diversas, e o braille convencional da imagem "f', impresso por meio de reglete em folhas de papel de gramatura $150 \mathrm{~g}$. O critério de seleção dos materiais de análise foi a diferença de relevo entre ambos. Para a realização dos testes, foi selecionada uma amostra de seis participantes com cegueira total (Quadro 1), divididos em três grupos com dois representantes cada: 1) grupo controle, com indivíduos não diabéticos; 2) grupo de diabéticos assintomáticos, ou seja, sem queixa de perda de sensibilidade nas mãos; e 3) grupo de diabéticos sintomáticos. Os testes foram conduzidos durante a aula de leitura em braille, havendo acompanhamento e orientação das atividades pela pedagoga da instituição.

Quadro 1: Dados dos participantes dos testes de leitura em braille

\begin{tabular}{|l|l|l|}
\hline grupo & idade & escolaridade e alfabetização em braille \\
\hline \multirow{2}{*}{ controle } & 19 anos & ensino médio completo / alfabetizada em braille \\
\cline { 2 - 3 } & 30 anos & ensino médio completo / fase inicial de alfabetização em braille \\
\hline \multirow{2}{*}{$\begin{array}{l}\text { diabéticos } \\
\text { assintomáticos }\end{array}$} & 31 anos & cursando ensino superior / alfabetizada em braille \\
\cline { 2 - 3 } & 54 anos & ensino fundamental incompleto / fase inicial de alfabetização em braille \\
\hline \multirow{2}{*}{$\begin{array}{l}\text { diabéticos } \\
\text { sintomáticos }\end{array}$} & 52 anos & ensino fundamental incompleto / fase de leitura e escrita em braille \\
\cline { 2 - 3 } & 64 anos & ensino fundamental incompleto / fase inicial de alfabetização em braille \\
\hline
\end{tabular}

Foram selecionadas nove palavras para o braille em papel e cinco para o adaptado, mantendo-se uma média de 35 células braille (caracteres) a serem lidas em ambos os materiais. Como os testes foram realizados durante a aula de braille, as leituras eram realizadas com os demais participantes presentes na sala, motivo pelo qual optou-se por selecionar palavras diferentes para cada indivíduo e para cada material. Os testes foram realizados em dois dias: no primeiro, foi feita a leitura com braille em papel; no segundo, a atividade com o braille adaptado. Em ambos os testes, foram adotados os mesmos procedimentos metodológicos.

Houve diferenças expressivas no tempo de leitura entre os grupos analisados, como demonstra o Quadro 2. Os maiores tempos referem-se ao grupo de diabéticos sintomáticos. 
Moura M., Portugal, C., Perez, I., Torres, M. A. \& Guimarães, M. | Design Contemporâneo e Inovação social aplicados no desenvolvimento de produtos gráficos educativos para pessoas com deficiência visual

Contudo, deve-se observar que outros fatores podem estar associados, uma vez que todos os participantes com tempo acima de 10 minutos tinham idade superior a 50 anos, não completaram o ensino fundamental e estavam em fase inicial de alfabetização em braille. Em alguns momentos, ambos os diabéticos sintomáticos apresentavam dificuldade em unir as letras para formar as sílabas e palavras. Dentre eles e o segundo diabético assintomático, era frequente a identificação errônea dos pontos e das células do braille. Mas também era recorrente o correto reconhecimento dos pontos não ser acompanhado da identificação da letra correspondente.

Quadro 2: Dados dos testes de leitura em braille realizados

\begin{tabular}{|l|l|l|l|l|}
\hline \multirow{2}{*}{ GRUPO } & \multicolumn{2}{l}{ BRAILLE EM PAPEL } & \multicolumn{2}{l}{ BRAILLE ADAPTADO } \\
\cline { 2 - 5 } & tempo & leitura & tempo & leitura \\
\hline \multirow{2}{*}{ controle } & 30 segundos & completa & 02 minutos & completa \\
\cline { 2 - 5 } & 05 minutos & completa & 02 minutos & completa \\
\hline \multirow{2}{*}{$\begin{array}{l}\text { diabéticos } \\
\text { assintomáticos }\end{array}$} & 06 minutos & completa & 05 minutos & completa \\
\cline { 2 - 5 } & 11 minutos & incompleta & 15 minutos & completa \\
\hline $\begin{array}{l}\text { diabéticos } \\
\text { sintomáticos }\end{array}$ & 18 minutos & completa & 27 minutos & completa \\
\cline { 2 - 5 } & 21 minutos & incompleta & 25 minutos & completa \\
\hline
\end{tabular}

Observa-se que, embora o tempo de leitura do braille adaptado tenha sido superior em alguns casos, notou-se mais dificuldade durante a leitura do braille em papel. Afinal, ainda que o tempo tenha sido inferior, dois participantes não conseguiram completar a leitura do braille em papel, seja por pular uma palavra ou por apenas identificar letras e sílabas isoladas, sem formar o vocábulo completo. Já no teste com o braille adaptado, todos conseguiram completar a leitura. Os resultados, portanto, sugerem que o braille adaptado é, de fato, mais adequado para iniciantes. Contudo, não é possível concluir que a perda de sensibilidade nos dedos decorrente da diabetes interfira na leitura, já que há outros fatores que podem estar associados à dificuldade de leitura.

\section{Considerações finais}

Os resultados até esse momento apontam que há muitas queixas relacionadas à dificuldade de aprender braille, principalmente por parte de idosos ou diabéticos que perderam sensibilidade nas pontas dos dedos. Contudo, a literatura consultada, assim como os testes realizados e a entrevista com a pedagoga, sugerem que talvez a maior dificuldade esteja relacionada a fatores como baixa escolaridade, idade em que se aprende o braille e falta de treino. Esses dados sugerem a necessidade tanto de materiais táteis sem braille, como de materiais que auxiliem no processo de aprendizagem do braille e de apuração do tato. No Lar Escola Santa Luzia, são utilizados materiais pedagógicos e conduzidas atividades que podem servir de inspiração no desenvolvimento de materiais gráficos inclusivos. Ademais, a equipe da instituição demonstra ter a competência necessária para participar de processos de Co criação desses materiais, os quais, ao serem disponibilizados em modo aberto (open design), supririam a lacuna já apontada pela pedagoga do Lar Escola, segundo a qual há carência de artefatos de aprendizagem de braille adaptados e de baixo custo.

O estudo aqui relatado, contudo, ainda encontra-se em fase inicial, motivo pelo qual os resultados apresentados são apenas parciais. Mais testes e entrevistas serão realizados, assim como outras atividades envolvendo o Lar Escola Santa Luzia e as demais instituições parceiras, antes que sejam desenvolvidos os primeiros materiais gráficos inclusivos. Mas, por 
Moura M., Portugal, C., Perez, I., Torres, M. A. \& Guimarães, M. | Design Contemporâneo e Inovação social aplicados no desenvolvimento de produtos gráficos educativos para pessoas com deficiência visual

hora, destaca-se que o emprego de processos de aprendizagem para pessoas com deficiência visual devem ser aplicados além da sala de aula, pois existe uma grande necessidade para as pessoas que adquiriram a deficiência visual em diferentes momentos da vida, especialmente, na fase adulta avançada e na velhice, incluindo-se aí além da cegueira, a baixa visão ou visão subnormal. Nesses casos, a aquisição de informações e conhecimentos torna-se essencial na relação com as atividades da vida cotidiana, pois esses sujeitos, em sua nova condição, têm de (re)aprender a se relacionar com o espaço, objetos, mobilidade, com as atividades corriqueiras, tais como, comer, vestir, cuidados pessoais, entre outros. Destaca-se que essas questões relacionam-se diretamente à aquisição da autonomia do indivíduo.

É premente o desenvolvimento de ações de design para a inovação social e, também, ações de políticas públicas destinadas a esse público, pois enfrentam inúmeras dificuldades na locomoção cotidiana, nos deslocamentos pelo bairro e pela cidade onde vivem. Equipamentos como caçambas com entulhos, árvores sem poda, lixeiras no espaço urbano ou na área residencial, comércio de ambulantes, placas de sinalização mal colocadas, rampas com términos problemáticos, tornam-se obstáculos perigosos causando acidentes e, muitas vezes, tornando-se intransponíveis e levam ao isolamento da pessoa com deficiência visual, especialmente os idosos. Esses ao se tornarem reclusos, isolados e solitários, enfrentam sérios problemas que agravam a sua condição aumentando a situação de dependência, a aceitação em sua condição, especialmente nos casos de cegueira adquirida e gerando uma série de transtornos que afetam a saúde mental e física.

Nesse cenário é essencial a atuação do design para a inovação em ações interdisciplinares com outros segmentos do design, tais como o Design de Informação, para atuar como instrumento social apto à resolução de problemas oriundos de questões emergentes que ganham notoriedade na sociedade.

O design na atualidade expande suas fronteiras de atuação sem deixar de lado os territórios que já lhe são atribuídos e caminha rumo a um pensamento global que constitui novas práticas de atuação por três vias: da revitalização de métodos e práticas próprios do design; das relações entre design e outras áreas de conhecimento; e, da utilização do design como instrumento social apto à resolução de problemas oriundos de questões emergentes que ganham notoriedade na sociedade.

O Design Contemporâneo atua perante as possibilidades e desafios de compreensão do ser humano em sua complexidade. Explora o universo do sensível e a ampliação da realidade para que, a partir do conhecimento construído pelo estudo e pesquisa bem fundamentados no caminho da observação, leitura e análise deste tempo, das pessoas e suas maneiras de constituir outros e novos modos de vida, sejam exploradas as possibilidades, projetos, produtos, objetos, ambientes e serviços. Esses, por sua vez, conferem voz e expressão às diversas sensibilidades e subjetividades diferenciadas alterando métodos, expandido percepções e diversidades. E, também, colaboram e contribuem de forma efetiva para a sociedade e os grupos sociais da atualidade concebendo projetos e produtos adequados a valorização humana na aquisição e desenvolvimento de conhecimentos. Fato que permite uma atuação de forma mais consciente com a realidade humana, favorecendo a inclusão dos sujeitos na sociedade e expandindo as possibilidades de inovação social.

A aplicação do design para a sociedade por meio de ações, mudanças, colaboração e no exercício político da cidadania é condição essencial para a educação e a formação do sujeito contemporâneo, principalmente nos aspectos relacionados à inclusão e às pessoas com deficiência.

\section{Agradecimento}

Ao CNPq - Edital Universal MCTIC/CNPq n. ${ }^{2} 28 / 2018$ 
Moura M., Portugal, C., Perez, I., Torres, M. A. \& Guimarães, M. | Design Contemporâneo e Inovação social aplicados no desenvolvimento de produtos gráficos educativos para pessoas com deficiência visual

\section{Referências}

Adam \& Calomeno (2014). Metodologia para adaptação de conteúdo editorial imagético para deficientes visuais. InfoDesign, Revista Brasileira de Design da Informação, São Paulo, V.9, N. 3, pp. $201-215$.

Associação Brasileira de Normas Técnicas. (2015). NBR 9050: Acessibilidade a edificações, mobiliários, espaços e equipamentos urbanos. $3^{\mathrm{a}}$ Ed. Rio de Janeiro: ABNT.

Ávila, M.; Alves, M. R.; Nishi, M. (2015). As condições de saúde ocular no Brasil. Conselho Brasileiro de Oftalmologia. Relatório.

Brasil. Presidência da República (2004). Decreto Federal 5.296 de 2 de dezembro de 2004. Recuperado em 25 abril, 2016, de http://www.planalto.gov.br/ccivil_03/_ato20042006/2004/decreto/d5296.htm

Brasil. Lei de acessibilidade (2000). Lei № 10.098 de 10 de dezembro de 2000. Recuperado em 10 março, 2015, de http://www.planalto.gov.br/ccivil_03/leis/L10098.htm

Bruno, M. M. G. (2006). Saberes e Práticas da Inclusão: Deficiência Visual. $4^{\text {a }}$ Ed. Brasília: MEC.

Cardeal, M. (2008). Imagem em Relevo: primeiros apontamentos sobre ilustração tátil em livros para crianças cegas.

Cardeal, M. (2011). Metáforas Visuais: redundâncias táteis. In: Duarte, M. Desenho infantil e seu ensino a crianças cegas: razões e métodos. Curitiba: Editora Insight.

Castro, M. B. et al. (2017). Fatores de risco para retinopatia diabética: uma revisão. Revista de Patologia do Tocantins, v. 4, n. 3, 2017: pp. 66-72.

Conselho Brasileiro de Oftalmologia - CBO (2012). As condições da saúde ocular no Brasil. São Paulo: CBO.

Cryer, H., \& Home, S. (2011). Feasibility of developing a diagnostic touch test to determine braille reading potential. RNIB Centre for Accessible Information (CAI): Birmingham, Reino Unido. Relatório de pesquisa.

Darras, B. \& Valente, D. (2011). Tactile images: semiotic reflections on tactile images for the blind. In: Revista Haptica, Paris. V. 1, n. 1.

Duarte, M. L. B. (2011). Desenho infantil e seu ensino a crianças cegas: Razões e Métodos. Curitiba: Insight.

Griffin, H. \& Gerber, P. (1996). Desenvolvimento tátil e suas implicações na educação de crianças cegas. In: Revista do Instituto Benjamin Constant, Rio de Janeiro. Ed. 05.

Inclusive Design Research Center (2015). What is inclusive design?. Disponível em: https://idrc.ocadu.ca/about-the-idrc/49-resources/online-resources/articles-andpapers/443-whatisinclusivedesign. Acesso em 03/05/2018.

Kastrup, V. (2007). A invenção na ponta dos dedos: a reversão da atenção em pessoas com deficiência visual. In: Psicologia em Revista, Belo Horizonte, v. 13, n. 1. pp. 69 - 90, jun. 2007. Recuperado em 13 novembro, 2015 de http//:www.portal.pucminas.br

Moura, M. (2015). Design Contemporâneo: reflexões. São Paulo: Estação das Letras e Cores.

Nuernberg, A. (2010). llustrações táteis bidimensionais em livros infantis: considerações acerca de sua construção no contexto da educação de crianças com deficiência visual. In: Revista Educação Especial, v. 23, n. 36.

Portugal. C. (2013). Design, Educação e Tecnologia. Rio de Janeiro: Riobooks.

Portugal, C. (2009). Design em Situações de Ensino-aprendizagem. Um diálogo Interdisciplinar. 2009. 206p. Tese (Doutorado em Design), Departamento de Artes \& Design. Pontifícia Universidade Católica do Rio de Janeiro. 
Moura M., Portugal, C., Perez, I., Torres, M. A. \& Guimarães, M. | Design Contemporâneo e Inovação social aplicados no desenvolvimento de produtos gráficos educativos para pessoas com deficiência visual

\section{Sobre o(a/s) autor(a/es)}

Monica Moura, PhD, UNESP, Brasil, monica.moura@unesp.br

Cristina Portugal, PhD, PUC Rio, Brasil, crisportugal@gmail.com

lana Uliana Perez, doutoranda, UNESP, Brasil, iana.uli@gmail.com

Maria AliceTorres, mestranda, UNESP, Brasil, malicetorres@gmail.com

Marcio Guimarães, doutorando, UNESP, Brasil, falecommg@gmail.com 